\title{
Thermodynamics of Ion Exchange Reaction in Predicting the Ionic Selectivity Behavior of UV Radiation Degraded Nuclear-grade and Non-nuclear Grade Resins
}

\author{
ASHOK NARHARI PATANGE* \\ Department of Chemistry, Bhavan's College, Munshi Nagar, Andheri (West), \\ Mumbai, Maharashtra 400058, India. \\ *Corresponding author E-mail: ashokpatange78@gmail.com \\ http://dx.doi.org/10.13005/ojc/3404044
}

(Received: May 09, 2018; Accepted: June 21, 2018)

\begin{abstract}
The study represents the evaluation of performance of structurally related resins Duolite ARA9366 and DuoliteA-378 exposed to UV radiations of wavelength $\lambda=254 \mathrm{~nm}$ and $\lambda=384 \mathrm{~nm}$ for $24 \mathrm{~h}$ in a UV Chamber and equilibrated separately with iodide ion solutions of different concentrations between temperature of $30.0^{\circ} \mathrm{C}-45.0^{\circ} \mathrm{C}$ for $5 \mathrm{~h}$ the equilibrium constants $(\mathrm{K})$ values for $\mathrm{Cl}-/ /$ - reactions with temperature for Duolite ARA-9366 were decreased from $21.57 \times 10^{-2}$ to $15.57 \times 10^{-2}$ for resin degraded at $\mathrm{UV}$ radiation of $384 \mathrm{~nm}$ was lower than the decrease in $\mathrm{K}$ values from $26.22 \times 10^{-2}$ to $19.92 \times 10^{-2}$ observed for the resin degraded at UV radiation of wavelength $\lambda=254 \mathrm{~nm}$. Similar results were obtained for Duolite A378.The UV degradation of the resin surfaces were recognized by SEM and IR. The high $\mathrm{K}$ and low enthalpy values obtained for Duolite ARA-9366 shows that Duolite ARA-9366 was more selective towards iodide ions in solution than Duolite A-378.
\end{abstract}

Keyword: Nuclear grade resins, Duolite ARA-9366, Duolite A-378 UV radiation degradation, Scanning Electron Microscopy (SEM) and Fourier Transform Infrared Spectroscopy (FTIR)

\section{INTRODUCTION}

Ion exchange is a process in which the mobile ions from external solutions were exchange with the ions that are bound to different functional groups in the resins. if the resin containing positively charged functional groups then the exchange involves negative ions in the external solution and if the resin contains negatively charged functional group then it will remove or exchange positively charged ions from external solutions. This principle of ion exchange were used in different industries ${ }^{1}$ and factories like chemical, nuclear, food, pharmaceutical color, drugs and dyes industries in order to remove the unwanted hard cations and hard anions in the process of manufacturing, synthesis and purification. lon exchangers were also used as phase transfer catalysis $^{2}$ in various potential pharmaceutical as

This is an Open Access article licensed under a Creative Commons Attribution-Non Commercial-Share Alike 4.0 International License (https://creativecommons.org/licenses/by-nc-sa/4.0/), which permits unrestricted Non Commercial use, distribution and reproduction in any medium, provided the original work is properly cited. 
important intermediate for drug and dyes synthesis. In recent years most of research work were carried out on characterization studies of various nuclear and industrial grade organic as well as inorganic ion exchanger under various stringent chemical, thermal, $\gamma$-rays radiation degradation ${ }^{3}$ condition so as to improve the performance, efficiency and selectivity behavior towards variety of cations and anions in the industrial waste effluents, purification and manufacturing process ${ }^{4}$ and the removal of radio nuclides from nuclear industries. In order to remove or separate radio nuclides and other ions from industrial waste it was very difficult to choose the suitable ion exchange resins for the separations of these ions so that there was need of some thermodynamic data or techniques which will provides the useful information about the various nuclear and industrial grade resins and helps to select which of the ion exchange resins were suitable for removal or separations of various cations and anions from industrial waste and nuclear waste. Taking in to the considerations and needs of industries attempts were made in the present research study to evaluate the performance ${ }^{6}$ of two closely related resins viz Duolite ARA9366 and Duolite A-378 under stringent degradation conditions like UV radiation of different wavelength in a UV chamber ${ }^{7}$ for $24 \mathrm{~h}$ separately for the resins and thermodynamic ion exchange equilibrium studies were carried out in predicting the selectivity behavior of these resins in chloride form towards the iodide ions of different ionic concentrations under the temperature range of $30.0-45.0^{\circ} \mathrm{C}$ for $5 \mathrm{~h}$ the thermodynamic data obtained from the study will helpful in predicting the selectivity behavior of the resins. The data obtained from the study will also be helpful for the selection of suitable ion exchange resin under the stringent degradation like UV radiations. The ion exchange equilibrium studies indicates that both resins shows strong absorption towards the longer UV wavelength at $\lambda=384 \mathrm{~nm}$ duo to the presence of conjugations and presence of quaternary and secondary amino groups for irradiation of the resins in UV radiation for longer period of time in UV chamber blocks the particular sites of the resin by reducing the ion exchangeable groups which will be responsible for the decrease in the equilibrium constant values and the enthalpy values of for $\mathrm{Cl}-/ \mathrm{l}$ - ion exchange reactions and consequently ${ }^{8}$ affects on the performance of the resins viz Duolite ARA9366 and Duolite A-378 which will also supported by the SEM micrographs and IR spectra of the degraded resin surfaces.

\section{MATERIALS AND METHODS}

\section{Materials}

The anion exchange resin DuoliteAR A9366 and Duolite A-378 in hydroxide ${ }^{9}$ form was supplied by the Auchtel chemicals limited, Mumbai were strongly basic nuclear grade and weakly basic non-nuclear grade anion exchange resin. The resin granules of mesh size 30-40 were used for the research work. Both the resins converted into chloride ion form for the experimental study by treating the respective resin sample with $20 \% \mathrm{KCl}$ solution for $24 \mathrm{~h}$ in a 50 $\mathrm{cm}$ long and $2.5 \mathrm{~cm}$ in diameter glass column at the rate of $1 \mathrm{ml}$ for 30 second after conditioning of the resin sample in chloride form were purified with help of distill water and ethanol solvent and air dried and stored in glass bottle.

\section{UV radiation degradation of resins}

In order to predict the performance and selectivity nature of the resins about $50 \mathrm{~g}$ of both resin ${ }^{10}$ sample in chloride form placed separately in an a UV chambers and irradiate them for $24 \mathrm{~h}$ continuously under UV radiation of wavelength $\lambda=254 \mathrm{~nm}$ and $\lambda=384 \mathrm{~nm}$. after $24 \mathrm{~h}$ both resin sample were drawn from the UV chambers ${ }^{11}$ and washed with distilled water and then with ethyl alcohol and air dried and stored in glass bottle and used for further study.

\section{Ion exchange equilibrium study}

For equilibration study about $1 \mathrm{~g}$ of UV radiation degraded resins viz Duolite ARA9366 and Duolite A-378 in chloride form were equilibrated ${ }^{12}$ separately with iodide ion solution of different ionic concentration from $0.01 \mathrm{M}, 0.02 \mathrm{M}, 0.05 \mathrm{M}, 0.08 \mathrm{M}$ and $0.10 \mathrm{M}$ on well-equipped magnetic stirrer with hot plate and automatic temperature control at the different temperatures from $30.0^{\circ} \mathrm{C}$ to $45.0^{\circ} \mathrm{C}$ for 5 $\mathrm{h}$ as explained ${ }^{12}$ After $5 \mathrm{~h}$ the quantity of iodide ions transfers with the resin surface can be determined potentiometrically by using standard $0.01 \mathrm{M} \mathrm{AgNO}_{3}$ using saturated calomel electrode as reference and silver electrode as indicator 
$\mathrm{D}-\mathrm{Cl}+\mathrm{I}-(\mathrm{aq})) \rightleftharpoons \mathrm{D}-\mathrm{I}+\mathrm{Cl}-(\mathrm{aq})$

$\mathrm{D}-\mathrm{Cl}+\mathrm{I}-(\mathrm{aq}) \rightleftharpoons \mathrm{D}-\mathrm{I}+\mathrm{Cl}-(\mathrm{aq})$

(1) Thus by knowing ${ }^{13}$ different ionic concentrations

(2) or amount of $\mathrm{I}^{-}$ions in solution transfers on the respective resin surface at a given temperature, $\mathrm{K}^{-}$values and mean $\mathrm{K}^{-}$values for this batch of experiment was determined. Similar $\mathrm{K}$ values were obtained for the $\mathrm{Cl}^{-} / \mathrm{I}^{-}$exchange reactions at different temperatures. the standard $\mathrm{Ho}$, Go and So in $\mathrm{kJ}^{\mathrm{mol}}{ }^{-1}$ of $\mathrm{Cl}^{-} / \mathrm{I}^{-}$ion exchange reactions for UV radiation degraded resin sample were determined from the slope obtained by plotting a graph of log $\mathrm{K}$ against 1/T (0 K) 14 (Fig.1-4). The thermodynamic parameters I and II were calculated by the equation

$\mathrm{K}=\frac{[\mathrm{D}-\mathrm{I}][\mathrm{Cl}-]}{[\mathrm{E}-\mathrm{D}-\mathrm{I}][\mathrm{I}-]}$

Here, $D=$ Duolite ARA-9366 = Duolite A-378 Surface; $E=$ ion exchange capacity of the resin
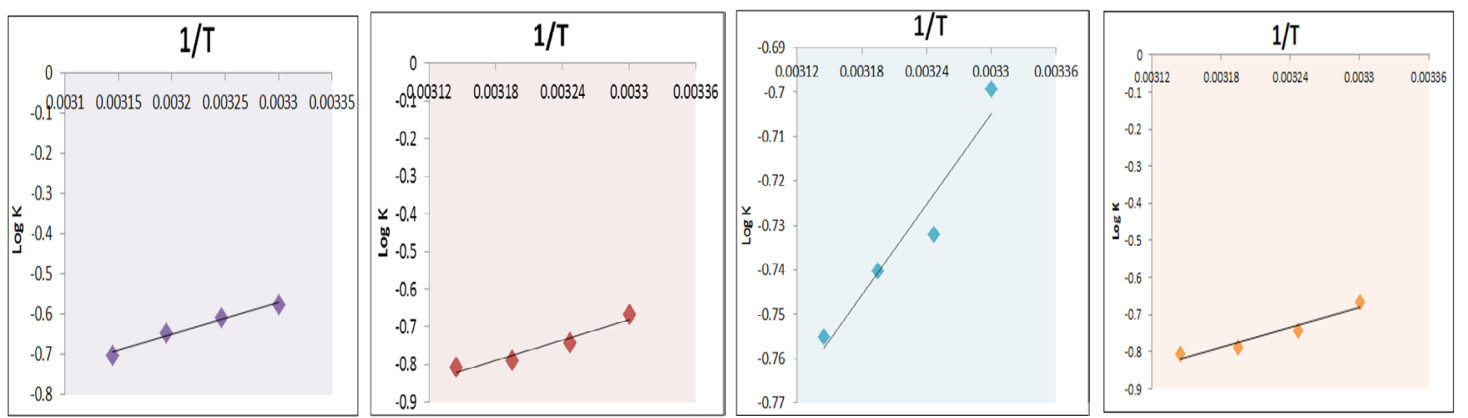

Fig. 1-4. Shows Variation of equilibrium constant for $\mathrm{Cl}^{-} /$. with temperature DuoliteARA-9366 \& Duolite A-378degraded at UV wavelength $\lambda=254 \mathrm{~nm}$ and $\lambda=384 \mathrm{~nm}$

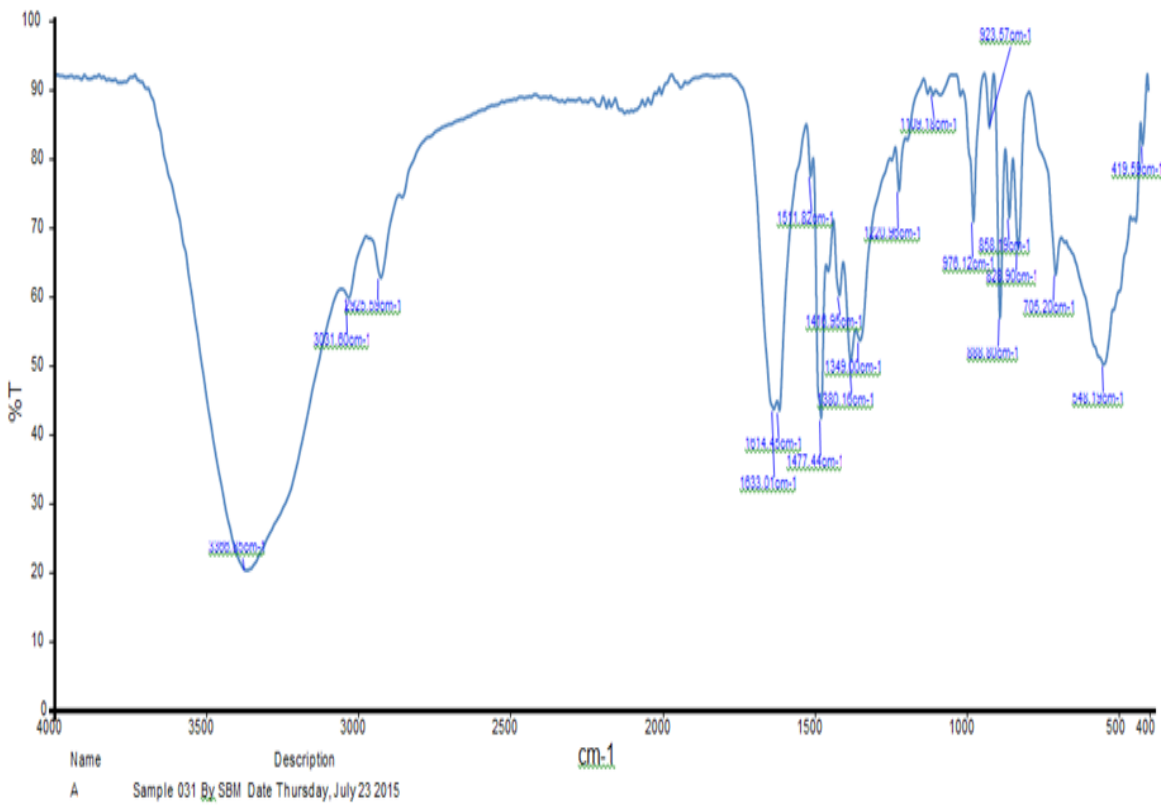

Fig. 5 


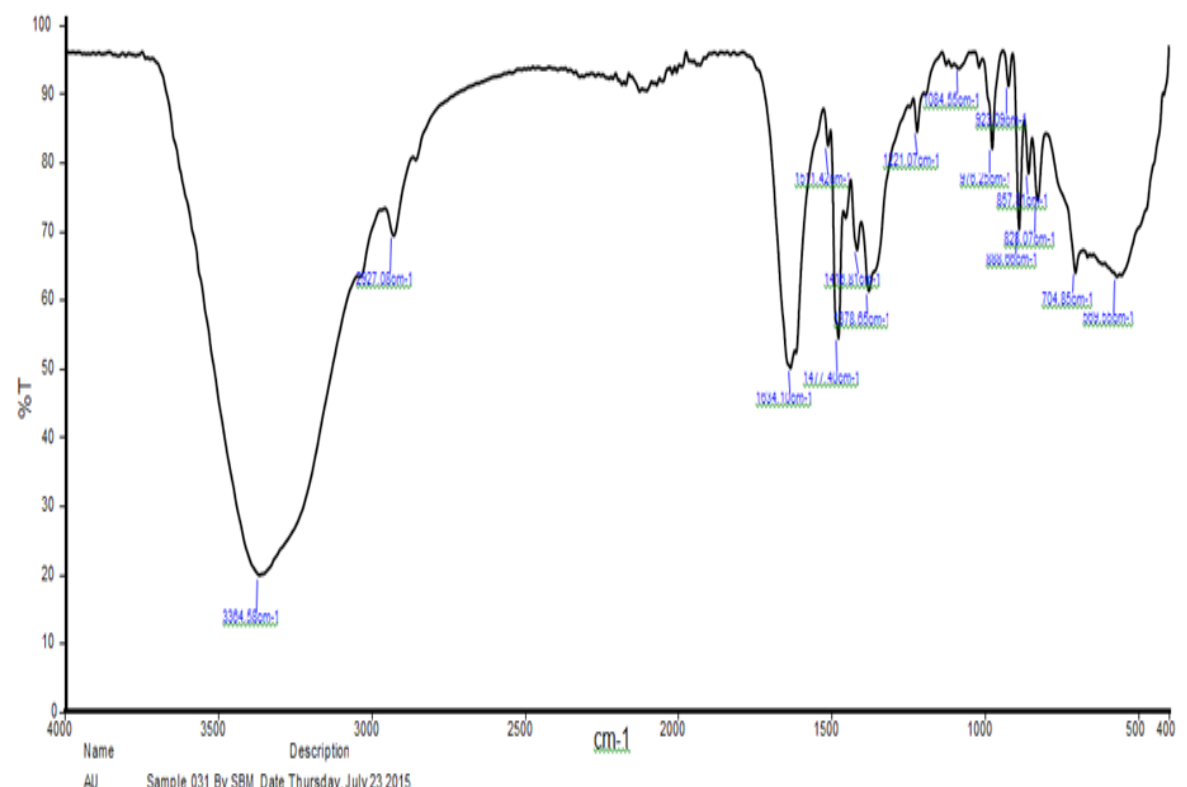

Fig. 6

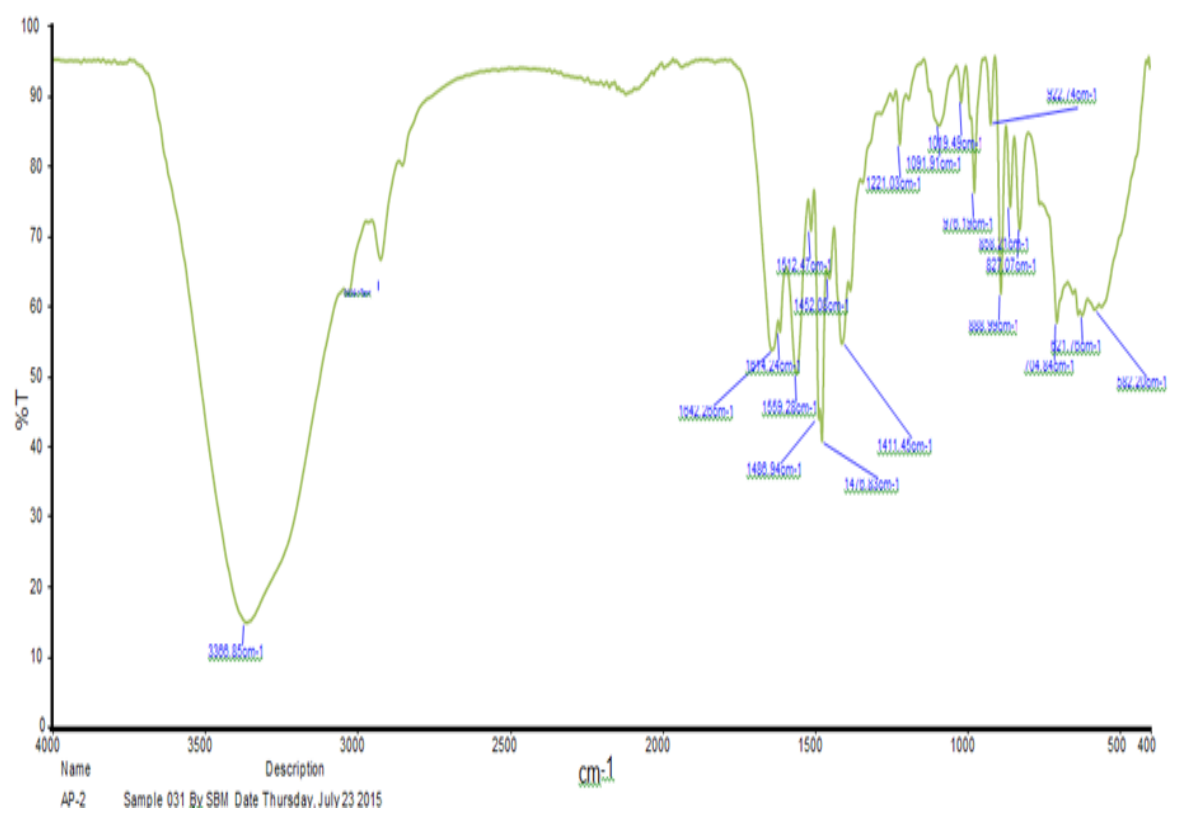

Fig. 7

Fig. 5-7. FTIR Spectrum of fresh resin, DuoliteARA-9366 Resin degraded at $\lambda=254 \mathrm{~nm}$ and $\lambda=384 \mathrm{~nm}$.

On observing the equilibrium constant (K)-values from Table 3-4 for $\mathrm{Cl}^{-} / \mathrm{I}^{-}$ion exchange reactions, the K-values for both UV degraded resins viz Duolite ARA9366 and Duolite A378 were found to be decreases with rise in temperature from $30.0^{\circ} \mathrm{C}$ to $45.0^{\circ} \mathrm{C}$ shows that $\mathrm{Cl}^{-/ /}$ion exchange reactions are exothermic in nature. The High K-values and low enthalpy values obtained for Duolite ARA9366 as compare to the K-values for Duolite A-378 resin indicates that the Resin Duolite ARA9366 was very selective or having greater affinity towards the iodide ions in solution as compares to Duolite A-378. the equilibrium constant (K-values) and enthalpy values obtained for both resins viz Duolite ARA9366 and 


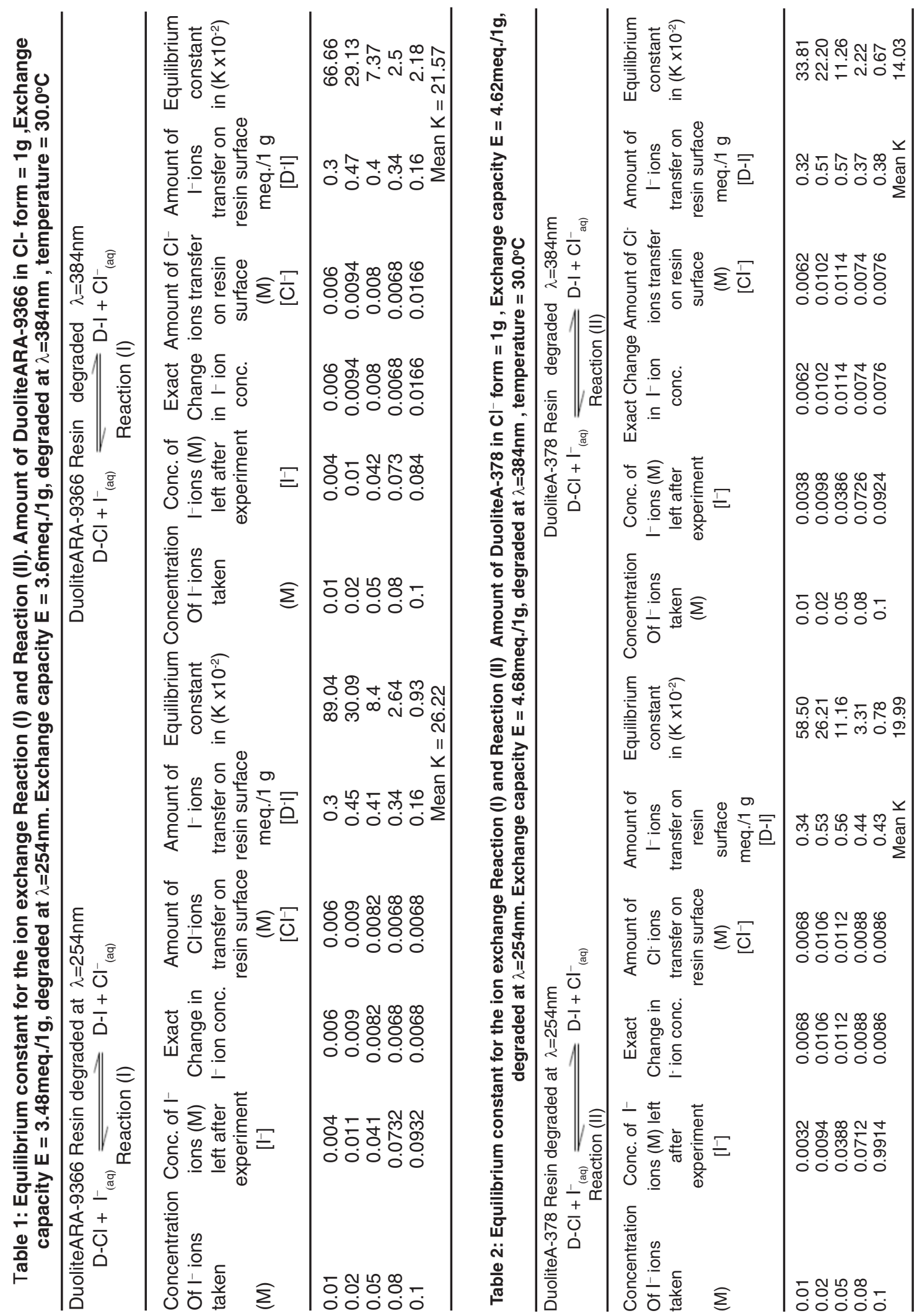


Table 3: Thermodynamics $\mathrm{Cl}^{-} / \mathrm{I}^{-}$reactions using Duolite ARA-9366 Resin degraded at $\lambda=254 \mathrm{~nm}$ and $\lambda=384 \mathrm{~nm}$

\begin{tabular}{|c|c|c|c|c|c|c|c|c|c|}
\hline \multirow{3}{*}{$\begin{array}{l}\text { Resins } \\
\text { Temperature }\end{array}$} & \multicolumn{4}{|c|}{$\begin{array}{l}\text { Duolite ARA-9366 degraded at UV wavelength } \\
\qquad \lambda=254 \mathrm{~nm}\end{array}$} & \multicolumn{5}{|c|}{$\begin{array}{l}\text { DuoliteARA-9366 degraded at UV wavelength } \\
\qquad \lambda=384 \mathrm{~nm}\end{array}$} \\
\hline & \multirow[t]{2}{*}{$\mathrm{D}-\mathrm{Cl}+\mathrm{I}_{(\mathrm{aq})}^{-}$} & \multicolumn{3}{|c|}{$\begin{array}{l}\rightleftharpoons \text { Reaction (I) } \\
\rightleftharpoons \mathrm{Cl}^{-} \text {(aq) }\end{array}$} & \multicolumn{2}{|c|}{$\mathrm{D}-\mathrm{Cl}+\mathrm{I}_{(\mathrm{aq})}^{-}$} & \multicolumn{3}{|c|}{$\underset{\text { Reaction (I) }}{\rightleftharpoons} \mathrm{D}-\mathrm{I}+\mathrm{Cl}^{-}{ }_{(\mathrm{aq})}$} \\
\hline & & $30.0^{\circ} \mathrm{C}$ & $35.0^{\circ} \mathrm{C}$ & $40.0^{\circ} \mathrm{C}$ & $45.0^{\circ} \mathrm{C}$ & $30.0^{\circ} \mathrm{C}$ & $35.0^{\circ} \mathrm{C}$ & $40.0^{\circ} \mathrm{C}$ & $45.0^{\circ} \mathrm{C}$ \\
\hline $\begin{array}{l}\text { Equilibrium } \\
\text { constant in }\left(\mathrm{K} \times 10^{-2}\right)\end{array}$ & & 26.22 & 24.65 & 22.58 & 19.92 & 21.57 & 18.07 & 16.27 & 15.57 \\
\hline $\mathrm{Ho}\left(\mathrm{kJ} \cdot \mathrm{mol}^{-1}\right)$ & & -14.55 & & & & & -19.03 & & \\
\hline Go $\left(\mathrm{kJ} . \mathrm{mol}^{-1}\right)$ & & 3.77 & & & & & 4.47 & & \\
\hline So $\left(\mathrm{kJ} \cdot \mathrm{mol}^{-1}\right)$ & & -0.058 & & & & & -0.061 & & \\
\hline
\end{tabular}

Table 4: Thermodynamics $\mathrm{Cl} / \mathrm{/l}$ reactions using Duolite A-378 Resin degraded at $\lambda=254 \mathrm{~nm}$ and $\lambda=384 \mathrm{~nm}$

\begin{tabular}{|c|c|c|c|c|c|c|c|c|}
\hline $\begin{array}{l}\text { Duolite A-378 } \\
\qquad \mathrm{D}-\mathrm{Cl}+\mathrm{I}^{-} \text {(aq) }\end{array}$ & $\begin{array}{l}\text { degraded } a \\
\overline{\lambda=254 \mathrm{~nm}} \\
\text { Reaction ( }\end{array}$ & $\begin{array}{l}\text { JV wavele } \\
\text { D-I + } \mathrm{Cl}^{-}\end{array}$ & & $\begin{array}{r}\text { Duc } \\
\text { D }\end{array}$ & $\begin{array}{l}\text { e A-378 } \\
+I^{-}\end{array}$ & $\begin{array}{l}\text { legradec } \\
=384 \mathrm{~nm} \\
\text { eaction ( }\end{array}$ & $\begin{array}{l}\text { at UV wi } \\
\rightleftharpoons \mathrm{D}-\mathrm{I}\end{array}$ & $\begin{array}{l}\text { velength } \\
\mathrm{Cl}^{-}{ }_{(\mathrm{aq})}\end{array}$ \\
\hline Temperature & $30.0^{\circ} \mathrm{C}$ & $35.0^{\circ} \mathrm{C}$ & $40.0^{\circ} \mathrm{C}$ & $45.0^{\circ} \mathrm{C}$ & $30.0^{\circ} \mathrm{C}$ & $35.0^{\circ} \mathrm{C}$ & $40.0^{\circ} \mathrm{C}$ & $45.0^{\circ} \mathrm{C}$ \\
\hline Equilibrium & & & & & & & & \\
\hline constant in $\left(\mathrm{K} \times 10^{-2}\right)$ & 19.99 & 18.54 & 18.19 & 17.58 & 14.03 & 13.50 & 12.82 & 12.27 \\
\hline $\mathrm{Ho}\left(\mathrm{kJ} . \mathrm{mol}^{-1}\right)$ & & -6.49 & & & & & -19.80 & \\
\hline Go $\left(\mathrm{kJ} \cdot \mathrm{mol}^{-1}\right)$ & & 4.34 & & & & & 5.24 & \\
\hline So $\left(\mathrm{kJ} \cdot \mathrm{mol}^{-1}\right)$ & & -0.034 & & & & & -0.063 & \\
\hline
\end{tabular}

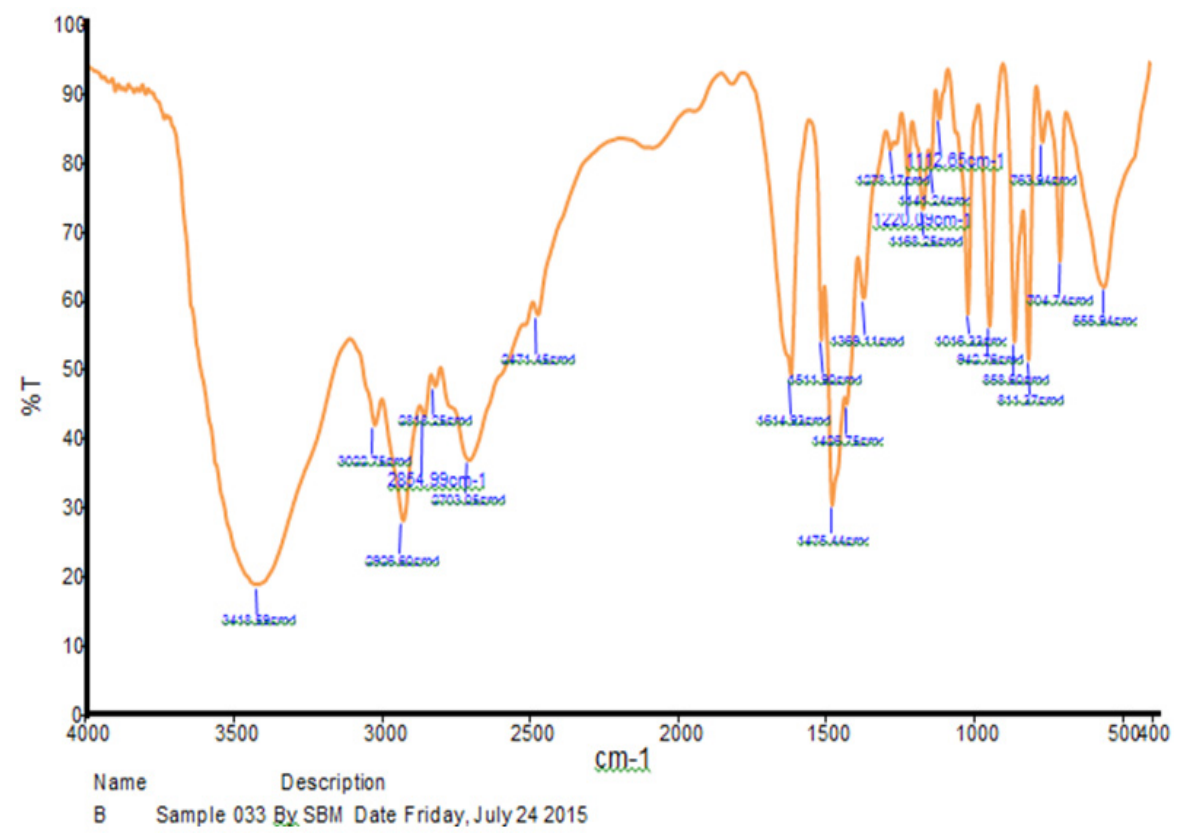

Fig. 8 


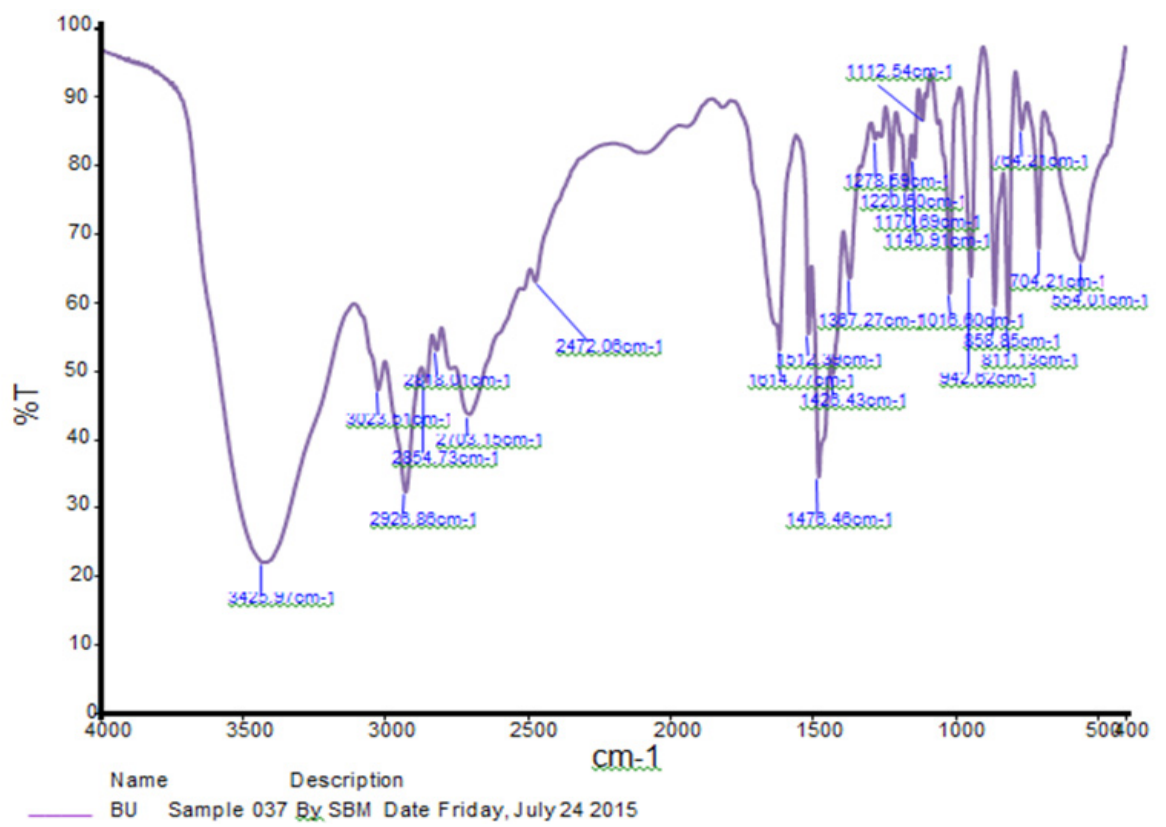

Fig. 9

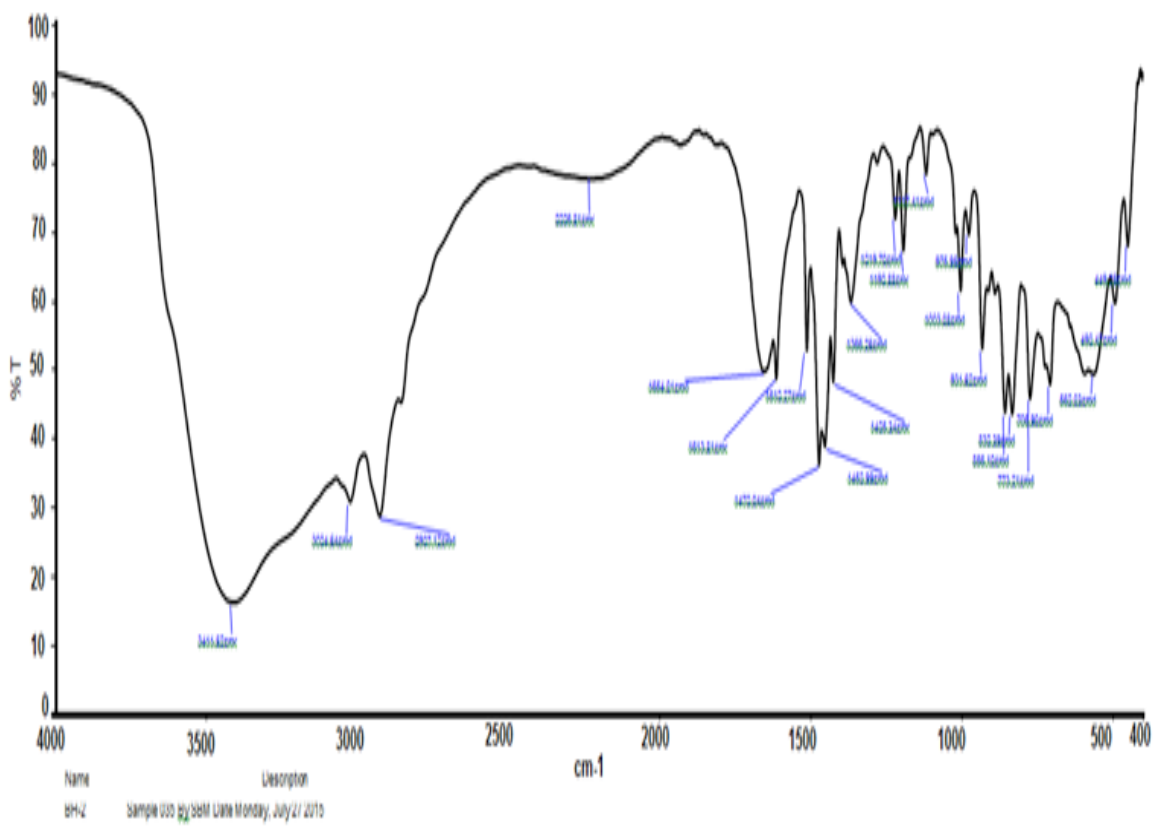

Fig. 10

Fig. 8-10. FTIR Spectrum of fresh resin, DuoliteA378 Resin degraded at $\lambda=254 \mathrm{~nm}$ and $\lambda=384 \mathrm{~nm}$

Duolite A378 degraded at $\lambda=384 \mathrm{~nm}$ will be lower than that the K-values and enthalpy values obtained for resins Duolite ARA9366 and Duolite A-378 exposed to UV light at $\lambda=254 \mathrm{~nm}$ this will shows that both resins strongly absorbs UV radiation of $384 \mathrm{~nm}$ which will results in decreasing the ion exchange functional groups in the polymer chain of the resin and lowers the rate of ion exchange reactions at the resin surface and decreasing the equilibrium constant value for ion exchange process. This also seen in the IR spectra and SEM images of the degraded resin surfaces (Figure 5-16). 


\section{Graphs}

IR Analysis of Duolite ARA-9366 and Duolite A-378 Resin degraded at $\lambda=254 \mathrm{~nm}$ and $\lambda=384 \mathrm{~nm}$

IR spectra of fresh as well as degraded samples of Duolite ARA-9366 and Duolite A378 resins ${ }^{15}$ were scan on Perkin Elmer 1750 FTIR spectrophotometer. Most of characteristic functional group of both fresh as well as UV degraded resins was found to be appears at the theoretical values but some considerable changes in some characteristic IR band were found to be broad in degraded resin sample duo to the strong absorption of UV wavelength at $\lambda=384 \mathrm{~nm}$ and crack the resin surface and lowers rate of ion exchange process which are also seen in SEM of both UV degraded resin sample.
SEM Analysis of Duolite ARA-9366 and Duolite A-378 Resin degraded at $\lambda=254 \mathrm{~nm}$ and $\lambda=384 \mathrm{~nm}$

SEM images of fresh and degraded resin surfaces were made exposed electronically in a vacuum on thin carbon layer for $60 \mathrm{sec}$ at $30 \mathrm{~W}$ and pictures were captured with help of JSM-6380LA mode ${ }^{16}$. On comparing the SEM micro graphs of fresh as well as UV irradiated resin surfaces, it will found that both resin were strongly absorbs UV radiation of wavelength $384 \mathrm{~nm}$ as comparing to $254 \mathrm{~nm}$ and due to this strong absorption $384 \mathrm{~nm}$ UV light surfaces ${ }^{17-18}$ of resin cracks and appears to more rough and enough to block the ion exchange site of the resin and consequently lowers down the ion exchange process as compare to fresh resin surfaces.

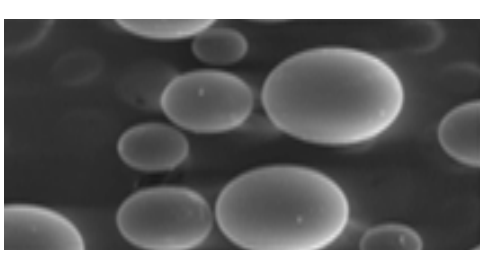

Fig. 11

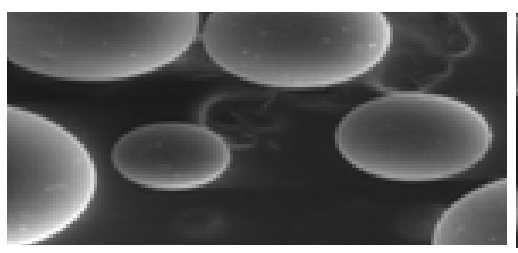

Fig. 12

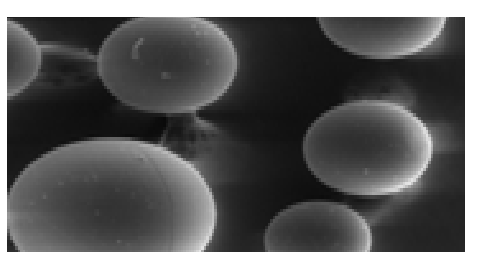

Fig. 13

Fig. 11-13. FTIR Spectrum of fresh resin, Duolite ARA9366 Resin degraded at $\lambda=254 \mathrm{~nm}$ and $\lambda=384 \mathrm{~nm}$

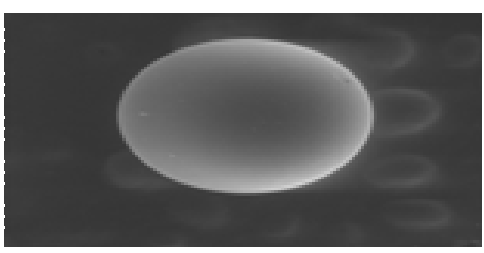

Fig. 14

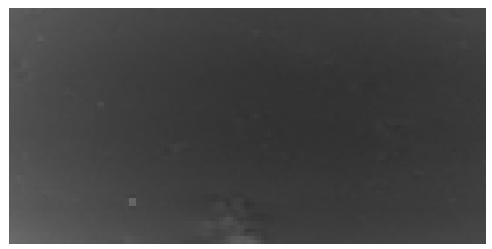

Fig. 15

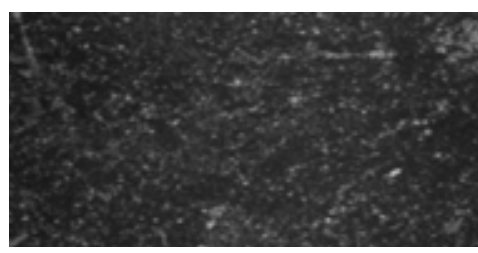

Fig. 16

Fig. 14-16. FTIR Spectrum of fresh resin Duolite A-378 Resin degraded at $\lambda=254 \mathrm{~nm}$ and $\lambda=384 \mathrm{~nm}$

\section{CONCLUSION}

The thermodynamic data obtained from the research study will be helpful in selecting the suitable ion exchange material for the removal of various cations and anions in the industrial waste, nuclear waste and removal of unwanted interfering ions in organic synthesis process. The results obtained from the work will also helpful for qualitatively assessing the efficiency, economy and performance of resins under the vigorous condition like chemical, thermal as well as under electromagnetic radiations.

\section{ACKNOWLEDGMENT}

The authors are thankful to Dr. V.G. Bhawe (Retired) Associate Professor and Dr.P.U.singare in Chemistry, BhavansCollege, Andheri(W) Mumbai for suggesting the research project and guidance during the entire research work. Author also be thankful to department of Nano Science and Nano technology of University of Mumbai for providing the sophisticated instrument facility for scanning and analysis of the SEM micrograph of fresh and degraded resin samples.

\section{REFERENCES}

1. Wiley, J.; and sons.: Inc. J. Appl polym Sci.,1997, 64, 1161-1167.
2. Baumann, E. ; J. Chem. and Eng. Data., 1960, $5,376$. 
3. Singare P.U; Patange, A.N.; ILCPA., 2014, 11, 67.

4. Singare P.U; Patange, A.N.; ILCPA., 2014, 11, 44 .

5 Singare P.U; Patange,A.N.; ILCPA., 2014, 6, 8.

6 Singare P.U; Patange,A.N.; ILCPA, 2014, 6, 1.

7. Patange,A.N.; Orient. J.Chem., 2017. 33(1), 430-438.

8. Bhargava, A.; Janardanan,C.; Indian J.Chem.,1997, 36A, 624.

9. Lokhande,R. S.; Singare, P. U.; Patil, A.; Russ. J. Phys. Chem., A, 2007, 81, 2059.

10. Patange,A.N.; GJESR., 2017, 4(8), 57-71.

11. Lokhande, R.S.; Singare, P.U; Radiochim.
Acta., 2007, 95, 173.

12. Lokhande,R.S.; Singare, P.U.; J .Porous Mater., 2008, 15, 253.

13. McNeill,I. C.; Mohammed, M.H.; Polym. Degrad. Stab., 1995, 48,175 .

14. Patange,A.N ;Singare P.U; Res. J. Pharm., Biol. Chem. Sci., 2017, 8(2),1866-1879.

15. Jiang,D.D.; Yao,Q.; McKinney, M.A.; Wilkie, C. A.; Polym. Degrad. Stab.,1999, 63, 423.

16. Decker, C.; Zahouily, K.; Polym. Degrad. Stab., 1999, 64, 293.

17. Santhiya, D.; Subramanian,S.; Natarajan, K.A.; Malghan, S. G.; J. Colloid. Int. Sci., 1999, 216, 143.

18. Kaczmarek, H.; Felczak, A.; Szalla, A.; Polym. Degrad. Stab., 2008, 93,1259. 